\title{
Comparative Evaluation of Effectiveness of Cisatracurium and Lidocaine in Alleviating Pain of Propofol Injection
}

\author{
Basant Singh Latwal and Amol Singam* \\ Jawaharlal Nehru Medical College, Datta Meghe Institute of Medical Sciences, Wardha - 442004, \\ Maharashtra, India; basantlatwal@gmail.com,dramolsingam@gmail.com
}

\begin{abstract}
Background and Aims: To compare the effectiveness and safety of Cisatracurium in preventing propofol Injection Pain (PIP) with that of Lidocaine. Methods/Statistical Analysis: In this Prospective, Randomized, Double blind, Comparative study, which was conducted at the Department of Anaesthesiology, Jawaharlal Nehru Medical College, DMIMS, Sawangi, Wardha, 60 patients with American Society of Anesthesiologists (ASA) class I and II aged 20-60 years, undergoing various type of surgeries under general anaesthesia with propofol as inducing agent and Cisatracurium as muscle relaxant, were divided into two equal groups of 30 each. In Group L (Lidocaine): Pretreatment with $0.5 \mathrm{mg} / \mathrm{kg}$ Lidocaine without preservative and In Group C (Cisatracurium): Pretreatment with $0.15 \mathrm{mg} / \mathrm{kg}$ Cisatracurium. Both the drugs were dispensed into the bigger dorsal vein of the hand with blood vessel occlusion for 30 seconds, followed by propofol $(0.5 \mathrm{mg} / \mathrm{kg})$ injection. The patients were assessed for pain every 10 seconds by asking whether they felt any pain on propofol injection, until the patient lost consciousness. The pain scoring was done using McCrirrick and Hunter scale. Statistical analysis was done using SPSS 23.0 and MedCalc 9.0.1. Findings: In the present research work, no obvious or significant difference relating to the incidence and severity of PIP was observed between the Lidocaine and Cisatracurium groups ( $p>=0.05$ ). The overall incidence of pain was $53.3 \%$ in the Lidocaine group, $46.6 \%$ in the Cisatracurium Group ( $p>=0.05)$. The incidence of severe pain was less in Group L (1/30) as compared to Group C (2/30) but it was nonsignificant. The incidence of Score ' 0 ' (no pain) in Group L was $46.6 \%$ and Group C was 53.33\%. Conclusion: Our study disclosed that Cisatracurium $(0.15 \mathrm{mg} / \mathrm{kg}$ ) effectively decreases the incidence and severity of pain evoked by Propofol injection with none important/significant complications.
\end{abstract}

Keywords: Cisatracurium, General Anaesthesia (GA), Lidocaine, Propofol Injection Pain (PIP), Propofol

\section{Introduction}

Propofol (2, 6-di-isopropylphenol), an intravenous anaesthetic agent with a shorter duration of action, is being used all over the world for induction and maintenance of general anaesthesia in children of age more than 3 years and adults and for sedation inside and outside the operation theater. As Propofol has a short duration of action, patients emerge quickly from its effect (prompt emergence). Like all anaesthetic agents, propofol also comes with its share of side effects and complications. Propofol Injection Pain (PIP), i.e. pain on its injection could be a common one ${ }^{1}$ and an awfully unpleasant one ${ }^{2}$. It is a common and frequently unfavorable effect and its prevalence extends from $30 \%$ to $90 \%$ in adults ${ }^{3}$.

The pain of propofol injection is thought to be the one of the most important disadvantages of its use as it causes stress during the induction phase. Although not a serious complication but for most patients, they remember it as one of the unpleasant encounters. Various elements

${ }^{*}$ Author for correspondence 
or factors appear to have an impact on the frequency or degree of pain, which include the size of vein, the location or site of delivery of the drug, the rate at which the drug is injected, efficiency of the blood as a buffer, the temperature at which the drug is maintained and associated use of medication ${ }^{4}$.

In order to decrease or to avoid PIP, various strategies have been tried with or without a tourniquet. Some of these interventions include pretreatment with Lidocaine ${ }^{5}$, Ketamine $^{6}$, Thiopental ${ }^{7}$, Ondansetron ${ }^{8}$, Dexamethasone ${ }^{9}$, Opioids ${ }^{10}$, Paracetamol ${ }^{11}$ and Dexmedetomidine ${ }^{12}$. Numerous different strategies like co-administration with Lidocaine, cooling or warming propofol ${ }^{13}$ and injection of propofol right into a larger vein have additionally been tried to prevent or to decrease propofol injection pain with varying success. The most productive approach up to date, to decrease or minimize the propofol injection pain, is the pretreatment of Lidocaine along with venous occlusion ${ }^{4}$. As with other techniques, this approach also has a failure rate indicating the need for alternative strategies for decreasing the PIP.

In the year 1908, August Bier described a technique of injecting the local anaesthetics intravenously to obtain regional anaesthesia which was later popularized as Bier block or IVRA (Intravenous regional anesthesia). In this technique, a local anaesthetic solution is injected into the venous system of an upper or lower extremity that has been isolated by means of a tourniquet from the central circulation. Cisatracurium (an isomer of Atracurium) is a muscle relaxant (belonging to the class of nondepolarizing skeletal muscle relaxant) for intravenous administration which acts on cholinergic receptors, blocking neuromuscular transmission. It has been shown that when Cisatracurium is added to the local anaesthetic solution for IVRA, it improves the efficacy and quality of the local anaesthetic solution ${ }^{14}$.

So, it was presumed that pretreatment with Cisatracurium under tourniquet control could lower the PIP.

Hence, the focus or aim of the current research work is at assessing the effectiveness of Cisatracurium pretreatment, for avoiding or reducing the pain associated with propofol injection, with the occlusion of the vein by tourniquet at the forearm and its comparison with Lidocaine.

\section{Materials and Methods}

After taking the approval from the institutional ethics committee, a prospective, comparative and randomized Study was carried out at the Department of Anaesthesiology, Jawaharlal Nehru Medical College, Datta Meghe Institute of Medical Sciences (DMIMS) and Acharya Vinoba Bhave Rural Hospital, Sawangi (Meghe), Wardha, Maharashtra. The present study was carried out on 60 patients. 60 patients were divided randomly and equally into 2 groups with 30 participants in each. Patients of both the sexes, between the age group of 20 to 60 years, were considered for the study who came under ASA class I, II and planned for various elective surgical procedures to be done under general anaesthesia with propofol as inducing agent and Cisatracurium as a muscle relaxant.

The exclusion norms for the study were as follows:

- Refusal of the patient for the study,

- Patients with ASA PS: III and above

- Patients with known cardiac disorders and other systemic disorders of lungs and liver,

- Patients with history of any neurological, neuromuscular or psychiatric illnesses,

- Parturient/expectant patients,

- History of Difficult intubation,

- Patients posted for emergency surgical operations or procedures,

- Patient with hypersensitivity (allergic) to Propofol or egg and Lidocaine,

- Have limited neck mobility,

- Those with history of motion sickness,

- History of post operative nausea and vomiting,

- On nasogastric tube, and

- Patients with anticipated difficult airway.

Using computer produced randomization, patients were divided into two groups. The anaesthesiologist who administered the medication was blinded from its constituents. Group L patients were premedicated with $2 \%$ Lidocaine, the dosage being $0.5 \mathrm{mg} / \mathrm{kg}$ and Group $\mathrm{C}$ patients were premedicated with Cisatracurium $0.15 \mathrm{mg} / \mathrm{kg}$.

Prior to surgery, a detailed pre-anaesthetic checkup of the patient was done. A thorough history of the patient was acquired and a complete or rigorous general physical examination of the patient was done. All the essential or necessary investigations, asked for, were completed. The patient and the relatives were given a detailed explanation 
regarding the procedure, its merits and demerits so as to reassure them and earn their confidence. Consent was also taken in writing both from the patient and the relatives regarding the same. All the patients were asked to be NBM (Nil by mouth) for at least 6 hours prior to the operation and premedicated with Tab. Alprazolam $0.25 \mathrm{mg}$, Tab. Ranitidine 150mg and Tab. Ondansetaron $4 \mathrm{mg}$ on the previous day(at night) of the surgery.

In the pre-operative room, all the patients were assessed for heart rate, respiratory rate per minute, blood pressure, saturation of the oxygen $\left(\mathrm{SPO}_{2}\right)$ and ECG changes, if any.

After the patient was taken to the surgical suite, electrocardiography, blood pressure (by a noninvasive method), and pulse oximetry were monitored. A standard intravenous cannula of size 20-G, the position or site of intravenous cannulation (most commonly on the nondominant hand), and the rate of fluid administration were kept same for all patients and it was continued according to the procedure in rest of intra-operative period. After a stabilization period of 10 minutes, a tourniquet was tied just proximal the elbow and Patient was given pretreatment solution, containing either Lidocaine (2\%) $0.5 \mathrm{mg} /$ $\mathrm{kg}$ (Group L) or $0.15 \mathrm{mg} / \mathrm{kg}$ of Cisatracurium (Group C) intravenously. After 30 seconds, the tourniquet was detached, and then Propofol (1\%) in the dose of $0.5 \mathrm{mg} / \mathrm{kg}$ was delivered by means of an intravenous cannula.

A synopsis of the trial method is given in Figure 1.

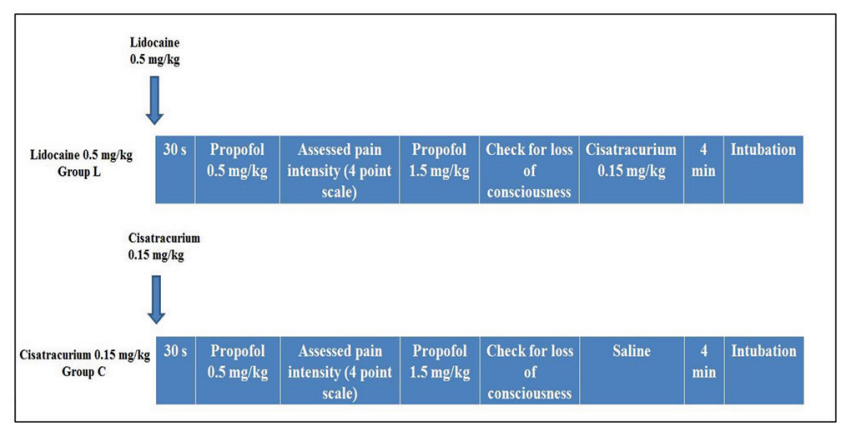

Figure 1. A synopsis of the trial method.

In order to evaluate the pain severity at the propofol injection site, we questioned the patient whether they felt any pain, first at 10 seconds then at the interval of 10 seconds and, if so, of what magnitude until the patient was unresponsive. The pain was assessed and graded using the Four-point pain scale of McCrirrick et al ${ }^{1 \frac{5}{5}}$ (Table 1).
The patient was observed for any voluntary or impulsive movements of the hand, arm, forearm, and shoulder and the findings were noted.

Table 1. Four-point pain scale according to the McCrirrick and Hunter Scale $\frac{15}{}$

\begin{tabular}{|c|c|l|}
\hline $\begin{array}{c}\text { Pain } \\
\text { score }\end{array}$ & $\begin{array}{c}\text { Degree of } \\
\text { pain }\end{array}$ & \multicolumn{1}{|c|}{ Response } \\
\hline 0 & None & \multicolumn{1}{|c|}{ No pain } \\
\hline 1 & Mild & $\begin{array}{l}\text { Mild pain (pain reported only in } \\
\text { response to questioning and without } \\
\text { behavioural signs) }\end{array}$ \\
\hline 2 & Moderate & $\begin{array}{l}\text { Moderate pain (pain reported in } \\
\text { response to questioning and with } \\
\text { behavioural signs, or pain reported } \\
\text { spontaneously without questioning) }\end{array}$ \\
\hline 3 & Severe & $\begin{array}{l}\text { Severe pain (strong verbal response } \\
\text { accompanied by facial grimacing, } \\
\text { withdrawal of hand and tears) }\end{array}$ \\
\hline
\end{tabular}

Every patient's highest pain score was noted.

The induction process was finished with Fentanyl 2-3 $\mu \mathrm{g} / \mathrm{kg}$ and Midazolam $0.03 \mathrm{mg} / \mathrm{kg}$ intravenously and the rest of the remaining dose of Propofol $(1.5 \mathrm{mg} / \mathrm{kg})$. Additional dose of muscle relaxant (Cisatracurium), making final dose to $0.15 \mathrm{mg} / \mathrm{kg}$ per patient, was given to facilitate intubation of Trachea. Intubation of the trachea was completed 4 minutes after giving the inducing dose of Cisatracurium.

Throughout the surgery, sevoflurane and nitrous oxide (66\%) in oxygen were used as an inhalational anaesthetic for the maintenance of anaesthesia intraoperatively with controlled ventilation. Muscle relaxation was maintained with the top-up doses of Cisatracurium. Post-surgery, the residual effect of neuromuscular blockade was antagonized with an anticholinesterase Neostigmine dosage being 0.05 $\mathrm{mg} / \mathrm{kg}$ with $0.5 \mathrm{mg}$ Gycopyrolate. Extubation was done once the patient was totally awake and obeying commands.

Adverse effects presumably due to propofol injection, like irritation, inflammation, oedema, weal, pain, allergic reactions at the site of injection, were looked for and noted in the following 24 hours after the surgery, utilizing strategies like spontaneous reporting and patient interview.

\subsection{Statistical Analyses}

After considering previous studies and past investigations and by keeping confidence intervals at 95\% ( $\alpha$ value of 0.05 ) and power at $80 \%$, our research work required a 
minimum of 25 patients in each group. 30 patients were included in each group to compensate for the potential dropouts.

The sample size was calculated using OpenEpi software.

Continuous pieces of information are reported as mean \pm standard deviation. Using student's t-test, age and other parameters like sex, weight, ASA physical status and height were compared between the groups. Chi-square test and Fisher's test were used to analyze the categorical figures in the form of frequencies and percentages. Statistical significance was considered when the value of $\mathrm{P}<0.05$. Statistical analysis was done using SPSS 23.0 and MedCalc 9.0.1

\section{Results}

An aggregate of 60 patients ( 31 men, 29 women) were incorporated in the present research (30 in each group). Both the groups were practically identical or similar as for the demographic information. As for the age, gender, stature, weight is concerned, no significant differences were found between the groups (Table 2).

Table 2. Demographic and clinical characteristics of study patients

\begin{tabular}{|c|c|c|c|}
\hline Characteristic & $\begin{array}{c}\text { Lidocaine } \\
\text { Group } \\
(\mathbf{N}=\mathbf{3 0})\end{array}$ & $\begin{array}{c}\text { Cisatracurium } \\
\text { Group (N=30) }\end{array}$ & $\begin{array}{c}\mathbf{P} \\
\text { Value }\end{array}$ \\
\hline Weight (Kg) & $66 \pm 11.9$ & $69 \pm 11.6$ & 0.326 \\
\hline Age (Years) & $45.6 \pm 11.4$ & $44.5 \pm 9.3$ & 0.683 \\
\hline Gender (M/F) \% & $\begin{array}{c}16(53.3 \%) \\
/ 14(46.7 \%)\end{array}$ & $\begin{array}{c}15(50 \%) / 15 \\
(50 \%)\end{array}$ & 0.799 \\
\hline $\begin{array}{c}\text { Height Mean } \\
(\mathrm{SD}), \mathrm{cm} .\end{array}$ & $169.66(4.32)$ & $168.10(4.27)$ & 0.164 \\
\hline ASA PS (I/II) & $\begin{array}{c}19(63.3) / \\
11(36.66)\end{array}$ & $21(70) / 9(30)$ & 0.58 \\
\hline
\end{tabular}

Values expressed as mean \pm SD or $\mathrm{n}(\%)$.

ASA PS - American Society of Anesthesiologists physical status;

$\mathrm{n}$ - Number of patients; SD - Standard deviation.

Statistically significant if $\mathrm{P}<0.05$ and

Statistically not significant if $\mathrm{P}>0.05$

The severeness of the pain in the two groups during propofol injection is shown in Figure 2.

In the Lidocaine group (L), $53.33 \%(16 / 30)$ of patients experienced pain. This rate was $46.66 \%(14 / 30)$

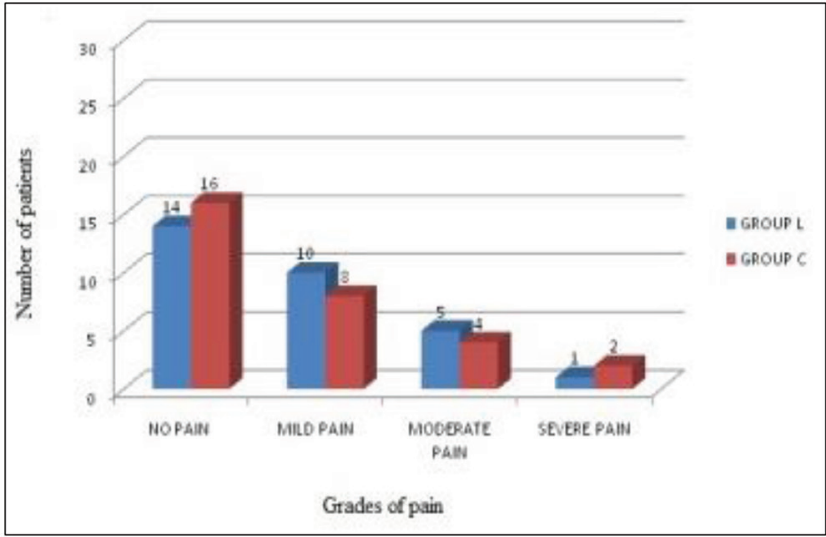

Figure 2. Pain severity.

in Cisatracurium group (C). Table 3 shows information regarding pain scores.

Table 3. Incidence of Pain (no. [\%] of Patients) in Study Population

\begin{tabular}{|l|c|c|c|}
\hline Pain Score & \multicolumn{1}{|c|}{$\begin{array}{c}\text { Lidocaine } \\
\text { Group } \\
(\mathbf{N}=\mathbf{3 0})\end{array}$} & $\begin{array}{c}\text { Cisatracurium } \\
\text { Group } \\
(\mathbf{N}=\mathbf{3 0})\end{array}$ & P Value \\
\hline $\begin{array}{l}\text { Any pain } \\
(1+2+3)\end{array}$ & $16(53.33 \%)$ & $14(46.66 \%)$ & 0.608 \\
\hline Pain Grade & \multicolumn{2}{|l|}{} & \\
\hline 0, none & $14(46.66 \%)$ & $16(53.33 \%)$ & 0.608 \\
\hline 1, mild & $10(33.33 \%)$ & $8(26.66 \%)$ & 0.576 \\
\hline 2, moderate & $5(16.66 \%)$ & $4(13.33 \%)$ & 0.7202 \\
\hline 3, severe & $1(3.33 \%)$ & $2(6.66 \%)$ & 0.557 \\
\hline
\end{tabular}

Data presented as - $\mathrm{n}(\%)$.

Statistically significant if $\mathrm{P}<0.05$ and

Statistically not significant if $\mathrm{P}>0.05$

Severe pain was experienced by $1 / 30$ patients (3.33\%) in group $\mathrm{L}$ and it was $2 / 30$ patients $(6.66 \%)$ in the group C. As for the prevalence of pain between the Lidocaine group and Cisatracurium group, no significant difference was found. Although fewer patients reported mild and moderate propofol injection pain in Cisatracurium group than in Lidocaine group, but the data is statistically nonsignificant $(\mathrm{p}>0.05)$ (Table 3$)$.

Complications like irritation, inflammation, pain, weal, oedema associated with propofol administration or 
injection, were not seen at the site of injection within the primary 24 hours of surgery.

\section{Discussion}

A calm and peaceful anaesthesia induction phase is important for patient's comfort and compliance. Unpleasant experiences during induction adversely affect the subsequent stages of anaesthesia. Propofol, which induces rapid, pleasant and comfortable loss of consciousness, has the significant disadvantage of causing a burning pain sensation during injection ${ }^{2}$. The pain can be immediate or delayed by $10-20$ seconds. This pain sometimes leads to an unnecessary stress during the induction phase.

Although the exact method of pain because of propofol administration has not been determined, the direct irritation of the vessel wall by the oil-emulsifying ${ }^{16,17}$ vehicle and the activation of kininogen-like pain mediators in the vessel wall have been implicated ${ }^{17}$.

The immediate vascular pain on propofol injection is due to a direct irritant effect of the drug by stimulation of receptors in the skin, mucous membrane and venous nociceptive receptors $\frac{18}{\underline{1}}$ or free nerve endings. The transmission of nerve impulse is by thinly myelinated $A-\delta$ fibres ${ }^{19}$.

Delayed pain is caused by the activation of the kallikrein-kinin system which causes release of the kinins, including bradykinin ${ }^{20}$, causing venous dilatation and hyperpermeability ${ }^{17}$.

The application of intravenous Lidocaine to decrease the propofol injection pain has been well established 5 ,21. Lidocaine seems to provide desirable effects in stopping or decreasing pain on injection by propofol. The method of action continues to be doubtful. A prior injection of Lidocaine caused a decrease in the severity of pain, presumably because of the immediate impact of local anaesthetics on vascular smooth muscular tissues (by using the reversible obstruction of peripheral nerve pathways ${ }^{22}$ or by means of modifications in the $\mathrm{pH}^{18,21}$.

It is realized and already known that neuromuscular junction blocking operators, for instance, Cisatracurium (non-depolarizing skeletal muscle relaxant), influence tactile nerve endings, nerve trunks and muscle spindles $\underline{23}, \underline{24}$. It has been proven that in order to reduce the pain experienced during and after the procedure, neuromuscular blocking agents are added (as an adjuvant) to the local anaesthetic during IVRA $\underline{24}-\underline{26}$. Consequently, it has been suggested that PIP may be reduced by Cisatracurium through the blockade of peripheral nerve endings via direct diffusion of the local anaesthetic from the vessels into the nearby nerves, followed by blockade of nerve trunks at a proximal site $e^{27}$.

The outcome of the current study stipulates a feasible pharmacological method which can reduce PIP and thus demonstrating that Cisatracurium, which is a NDMR, can be used as an acceptable alternative to Lidocaine, Ketamine, Ondansetron, Granisetron, Dexamethasone, Opioids, NSAIDs, Dexmedetomidine and other drugs for reducing PIP.

Since Cisatracurium is a NDMR, it can be used for muscle relaxation during general anaesthesia, thereby rendering it a major advantage over other drugs used for reducing PIP.

Thus using Cisatracurium would not only decrease the need for other muscle relaxants during the procedure but it would also prevent the reactions or side effects from the use of additional drugs for decreasing propofol related pain during induction.

The reporter did not notice any signs and symptoms of muscular fatigue or weakness or any evidence of respiratory trouble in the present study during the propofol administration.

In our study, $53.33 \%$ of the cases had no pain and $26.6 \%$ had mild pain in the Cisatracurium group which is comparable to the study conducted by Yun-Hee Kim et $\mathrm{al} \frac{28}{2}$ who compared Lidocaine and Cisatracurium pretreatment in different doses for the reduction of PIP. In the the study by Yun-Hee Kim et al, it was inferred that the prevalence of pain was altogether lower in the Lidocaine $(0.5 \mathrm{mg} / \mathrm{kg})$ group and Cisatracurium $(0.15$ $\mathrm{mg} / \mathrm{kg}$ ) group in comparison to the control (Normal Saline) group and $0.03 \mathrm{mg} / \mathrm{kg}$ Cisatracurium group. They concluded that the differences in the incidence of pain between the control (Normal Saline) group and $0.03 \mathrm{mg} / \mathrm{kg}$ Cisatracurium groups or between the Lidocaine and $0.15 \mathrm{mg} / \mathrm{kg}$ Cisatracurium groups were found to be insignificant.

Because the onset of Cisatracurium takes 3 to $5 \mathrm{~min}$ after delivery of the drug, the muscle weakness related to it was no longer a concern in the present study as the propofol was administered within the 30 s of the tourniquet release. 


\section{Conclusion}

Pretreatment with $0.15 \mathrm{mg} / \mathrm{kg}$ of Cisatracurium with venous occlusion for 30 seconds is as effective and as viable as intravenous Lidocaine pretreatment in alleviating the propofol injection pain and maybe a beneficial alternative for lowering pain on propofol injection without any significant complications in general anaesthesia.

\section{Limitations}

- Use of tourniquet is one of the limitations in this research work as without tourniquet the study drug would go into systemic circulation. Since we wanted the drug to remain locally in the upper arm to produce its effect, tourniquet use was important for this study.

- The subjective nature of the McCrirrick's Four-point pain scale is another Limitation in our study.

\section{References}

1. Baker MT, Naguib M. Propofol: the challenges of formulation, Anesthesiology. 2005; 103(4):860-76. https:// doi.org/10.1097/00000542-200510000-00026. PMid: 1619 2780.

2. Bryson HM, Fulton BR, Faulds D. Propofol: An update of its use in anaesthesia and conscious sedation, Drugs. 1995; 50(3):513-59. https://doi.org/10.2165/00003495199550030-00008. PMid: 8521772.

3. Sim JY, Lee SH, Park DY, Jung JA, Ki KH, Lee DH. Pain on injection with microemulsion propofol, British Journal of Clinical Pharmacology. 2009; 67(3):316-25. https://doi. org/10.1111/j.1365-2125.2008.03358.x. PMid: 19220277, PMCid: PMC2675042.

4. Jalota L, Kalira V, George E, Shi YY, Hornuss C, Radke O. Prevention of pain on injection of propofol: Systematic review and meta-analysis, British Medical Journal (BMJ). 2011; 342:111-20. https://doi.org/10.1136/bmj.d1110. PMid: 21406529.

5. Kaya S, Turhanoglu S, Karaman H, Özgün S, Basak N. Lidocaine forprevention of propofolinjection-induced pain:aprospective, randomized, double-blind, controlled study of the effect of duration of venous occlusion with a tourniquet in adults, Current Therapeutic Research. 2008; 69(1):29-35. https:// doi.org/10.1016/j.curtheres.2008.02.005. PMid: 2469278 z0, PMCid: PMC3969971.

6. Barbi E, Marchetti F, Gerarduzzi T, Neri E, Gagliardo A, Sarti A. Pretreatment with intravenous ketamine reduces propofol injection pain, Pediatric Anesthesia. 2003; 13(9):764-68. https://doi.org/10.1046/j.1460-9592.2003.01150.x. PMid: 14617116.

7. Agarwal A, Ansari MF, Gupta D, Pandey R, Raza M, Singh PK, et al. Pretreatment with thiopental for prevention of pain associated with propofol injection, Anesthesia and Analgesia. 2004; 98(3):683-86. https://doi.org/10.1213/01. ANE.0000103266.73568.18. PMid: 14980919.

8. Ambesh SP, Dubey PK, Sinha PK. Ondansetron pretreatment to alleviate pain on propofol injection: A randomized, controlled, double-blinded study, Anesthesia and Analgesia. 1999; 89(1):197-99. https://doi.org/10.1213/00000539199907000-00035.

9. Singh M, Mohta M, Sethi AK, Tyagi A. Efficacy of dexamethasone pretreatment for alleviation of propofol injection pain, European Journal of Anaesthesiology. 2005; 22(11):888-90. https://doi.org/10.1017/S026502150522 1506. PMid: 16225728.

10. Iyilikci L, Balkan BK, Gökel E, Günerli A, Ellidokuz H. The effects of alfentanil or remifentanil pretreatment on propofol injection pain, Journal of Clinical Anesthesia. 2004; 16(7):499-502. https://doi.org/10.1016/j. jclinane.2004.01.005. PMid: 15590252.

11. El-Radaideh KM. Effect of pretreatment with lidocaine, intravenous paracetamol and lidocaine-fentanyl on propofol injection pain: comparative study, Brazilian Journal of Anesthesiology. 2007; 57(1):32-38.

12. Ayoğlu H, Altunkaya H, Özer Y, Yapakçı O, Cukdar G, Özkoçak I. Does dexmedetomidine reduce the injection pain due to propofol and rocuronium? European Journal of Anaesthesiology. 2007; 24(6):541-45. https://doi. org/10.1017/S0265021506002250. PMid:17241503.

13. Ozturk E, Izdes S, Babacan A, Kaya K. Temperature of propofol does not reduce the incidence of injection pain, Anesthesiology: Journal of the American Society of Anesthesiologists. 1998; 89(4):1041-41. https://doi. org/10.1097/00000542-199810000-00039. PMid: 9778030.

14. Esmaoglu A, Akin A, Mizrak A, Turk Y, Boyaci A. Addition of cisatracurium to lidocaine for intravenous regional anesthesia, Journal of Clinical Anesthesia. 2006; 18(3):194-97. https://doi.org/10.1016/j.jclinane. 2005.08.003. PMid: 16731321.

15. McCrirrick A, Hunter S. Pain on injection of propofol: the effect of injectate temperature, Anaesthesia. 1990; 45(6):443-44. https://doi.org/10.1111/j.1365-2044.1990. tb14329.x. PMid: 2200300.

16. Johnson RA, Harper NJN, Chadwick S, Vohra A. Pain on injection of propofol Methods of alleviation, Anaesthesia. 1990; 45(6):439-42. https://doi. org/10.1111/j.1365-2044.1990.tb14328.x. PMid: 2200299. 
17. Scott RPF, Saunders DA, Norman J. Propofol: clinical strategies for preventing the pain of injection, Anaesthesia. 1988; 43(6):492-94. https://doi. org/10.1111/j.1365-2044.1988.tb06641.x. PMid: 3261547.

18. Eriksson M, Englesson S, Niklasson F, Hartvig P. Effect of Lidocaine and $\mathrm{pH}$ on propofol-induced pain, British Journal of Anaesthesia. 1997; 78(5):502-06. https://doi. org/10.1093/bja/78.5.502. PMid: 9175962.

19. Arndt JO, Klement W. Pain evoked by polymodal stimulation of hand veins in humans, Journal of Physiology. 1991;440(1):467-78. https://doi.org/10.1113/jphysiol.1991. sp018719. PMid: 1804973, PMCid: PMC1180163.

20. Nakane M, Iwama H. A potential mechanism of propofolinduced pain on injection based on studies using nafamostat mesilate, British Journal of Anaesthesia. 1999; 83(3):397-404. https://doi.org/10.1093/bja/83.3.397. PMid: 10655909.

21. Brooker J, Hull CJ, Stafford M. Effect of Lidocaine on pain caused by propofol injection, Anaesthesia. 1985; 40(1):91-92. https://doi.org/10.1111/j.1365-2044.1985. tb10530.x. PMid: 3871594.

22. Nicol ME, Moriarty J, Edwards J, Robbie DS, A'Hern RP. Modification of pain on injection of propofol-a comparison between Lidocaine and procaine, Anaesthesia. 1991; 46(1):67-69. https://doi.org/10.1111/j.1365-2044.1991. tb09323.x. PMid: 1996763.
23. Suppan P. Use of atracurium in the presence of lower or upper limb tourniquets, British Journal of Anaesthesia. 1984; 56(8):930-31. https://doi.org/10.1093/bja/56.8.930.

24. McGlone R, Heyes F, Harris P. The use of muscle relaxant to supplement local anaesthetics for Bier's blocks, Emergency Medicine Journal. 1988; 5(2):79-85. https:// doi.org/10.1136/emj.5.2.79. PMid: 3408537, PMCid: PMC1285492.

25. Elhakim M, Sadek RA. Addition of atracurium to lidocaine for intravenous regional anaesthesia, Acta Anaesthesiologica Scandinavica. 1994; 38(6):542-44. https://doi.org/10.1111/j.1399-6576.1994.tb03948.x. PMid: 7976142.

26. TorranceJM, Lewer BM, Galletly DC.Low-dose mivacurium supplementation of prilocaineiv regional anaesthesia, British Journal of Anaesthesia. 1997; 78(2):222-23. https:// doi.org/10.1093/bja/78.2.222. PMid: 9068344.

27. Risdall JE, Young PC, Jones DA, Hett DA. A comparison of intercuff and single cuff techniques of intravenous regional anaesthesia using $0.5 \%$ prilocaine mixed with technetium 99m-labelled BRIDA, Anaesthesia. 1997; 52(9):842-48. https://doi.org/10.1111/j.1365-2044.1997.175-az0309.x. PMid: 9349063.

28. Kim YH, Namgung J, Lim CH. Cisatracurium pretreatment with tourniquet reduces propofol injection pain: A doubleblind randomized controlled trial, Journal of International Medical Research. 2014; 42(2):360-67. https://doi. org/10.1177/0300060514522602. PMid: 24573971. 